\title{
Territorialidad indígena y políticas oficiales de colonización: los casos de Azul y Tapalqué en la frontera sur bonaerense (siglo XIX)
}

\author{
Territorialidade indígena e políticas oficiais de colonização: \\ os casos de Azul e Tapalqué na fronteira sul-bonaerense (século \\ XIX)
}

\author{
Sol Lanteri* \\ Silvia Ratto** \\ Ingrid de J ong ${ }^{* * *}$ \\ Victoria Pedrotta***
}

\section{RESUMEN}

El objetivo del trabajo es realizar un primer análisis de forma conjunta sobre las políticas de tierras y colonización fronteriza llevadas adelante por los gobiernos de la provincia -y luego Estado- de Buenos Aires, en lo que respecta a los pobladores criollos e indígenas que se asentaron en la campaña bonaerense. Se focaliza la atención en el extremo sur de la provincia, en la región de Azul y Tapalqué, en donde convergieron dos peculiaridades: la entrega de extensiones medianas de tierras a pobladores criollos y una concentración poblacional indígena que superaba ampliamente la cantidad de vecinos "blancos". Se rescata la importancia de la territorialidad indígena y campesina en la implementación de las medidas oficiales para la expansión de la frontera, en el marco del afianzamiento de la soberanía estatal y la articulación productiva hacia el mercado externo. Se destacan asimismo los cambios y continuidades habidas desde el inicio de la colonización regional a principios del siglo XIX, hasta la unificación del Estado a fines de dicha centuria.

Palabras Clave: Frontera. Políticas oficiales. Relaciones interétnicas. Territorialidad. Siglo XIX.

\section{ABSTRACT}

The aim of this work is to make a first joint analysis of the policies of land occupation and frontier colonization carried out by the government of Buenos Aires province - later State of Buenos Aires- in which it concerns both criollo and indigenous populations settled in the countryside. Attention is focused in the Southern end of the province, Tapalqué and Azul region, in where two peculiarities converged: the delivery of medium portions of land to criollo settlers and a concentration of indigenous population that surpassed widely the amount of "white" neighbors. The importance of indigenous and farmer's territoriality into the implementation of official devices for borderland expansion is rescued, framed by the reinforcement of the state sovereignty and the productive articulation towards the external market. The changes and continuities from the start of the regional colonization at the beginning of $19^{\text {th }}$ century, up to the unification of the national State by the end of that century, are also marked.

KEYWORDS: Borderland. Official policies. Interethnic relationships. Territoriality. 19 ${ }^{\text {th }}$ century.

\footnotetext{
* Doctora en Historia por la Universidad del Centro de la Provincia de Buenos Aires (UNICEN) y Becaria Postdoctoral e Investigadora designada del Consejo Nacional de Investigaciones Científicas y Técnicas (CONICET) / Argentina

** Doctora en Historia por la Universidad de Buenos Aires (UBA), Profesora de la Universidad Nacional de Quilmes e Investigadora del CONICET / Argentina

*** Doctora en Ciencias Antropológicas por la UBA, Profesora de la UBA e Investigadora del CONICET / Argentina

**** Doctora en Ciencias Naturales por la Universidad Nacional de La Plata, Profesora de la UNICEN e Investigadora del CONICET / Argentina
} 


\section{Introducción}

La historiografía argentina ha tendido, hasta hace poco, a marcar un fuerte quiebre en torno a mediados del siglo XIX al analizar los procesos políticos y económicos del actual territorio nacional. En ese sentido, la caída de Rosas en 1852 surgía como un parte aguas del proceso histórico y la década de 1850 como un tiempo de espera hacia la lenta unificación nacional. Estudios recientes han tendido a modificar esta imagen y, desde diversas perspectivas, se apunta a buscar los cambios pero también las continuidades entre la primera y la segunda mitad del siglo XIX. Este trabajo se inscribe en esa línea y su objetivo es iniciar un estudio sobre las políticas de tierras y colonización fronteriza llevadas adelante por los gobiernos de la provincia, y luego del Estado de Buenos Aires, tanto en lo que respecta a los pobladores criollos como a los indígenas que se asentaron en la campaña bonaerense. Se focaliza la atención en el extremo sur de la provincia de Buenos Aires, la región de Azul y Tapalqué, en donde convergieron dos peculiaridades: la entrega de extensiones medianas de tierras a pobladores criollos y una concentración poblacional indígena que superaba ampliamente la cantidad de vecinos "blancos" en el segundo de los partidos mencionados.

El trabajo está organizado en distintos apartados. En el primero se hará mención a los orígenes de los asentamientos criollos e indígenas en la región, realizados durante el gobierno de J uan Manuel de Rosas. En el segundo se analizará la década de 1850, cuando la estabilidad fronteriza se vio conmocionada por el intento del gobierno de expulsar hacia el sur a algunos antiguos pobladores indígenas de la región, provocando una violencia interétnica que se extendió por varios años. En el tercero, se presentarán las características que asumió la política de tierras durante las décadas de 1860 y 1870, una vez unificado el Estado. En el marco de un conjunto de medidas tendientes a asegurar la expansión de la ocupación "blanca" (criolla e inmigrante) y la incorporación de nuevas tierras a la producción rural en vinculación con el mercado atlántico, esas décadas muestran grandes contrastes en cuanto a la política sostenida hacia los asentamientos indígenas de la frontera, hasta su definitiva expulsión hacia finales de la centuria. Paralelamente se dio la implementación de modalidades de usufructo y apropiación legal de los terrenos fiscales, como intentos de ordenar e institucionalizar la situación de la etapa anterior. Este proceso presenta, a su vez, características particulares según las jurisdicciones fronterizas, sobre las que intentamos avanzar y reflexionar en nuestras conclusiones. 


\section{Los Inicios del Asentamiento Durante el Gobierno de J uan Manuel de Rosas}

Durante la época colonial, el límite oficial de demarcación de los territorios indígena e hispano-criollo en la actual provincia de Buenos Aires fue el río Salado, aunque el mismo era frecuentemente traspuesto por sus habitantes por cuestiones comerciales y laborales (RATTO, 2003a). El proceso revolucionario no produjo cambios de significación en lo relativo a dicha delimitación territorial pero, a partir de 1820 y luego de la caída del gobierno central que había intentado mantener unido el ex Virreinato del Río de la Plata, el Estado de Buenos Aires comenzó una expansión oficial sobre la frontera sur en pleno proceso de "expansión ganadera", mediante la fundación de pueblos y sedes de poder institucional y la cesión de tierras fiscales, entre otras medidas (HALPERIN DONGHI, 1963; CANSANELLO, 2003; BARRAL; FRADKIN, 2007). En este contexto, la colonización de la región de Azul presentó características distintivas porque fue impulsada por el gobierno de J uan Manuel de Rosas (1829-32 y 1835-52) mediante una serie de donaciones condicionadas de "suertes de estancia" terrenos de 2.025 hectáreas (has) cada uno- que se efectivizaron a partir de 1832 (INFESTA, 1994). Las dimensiones de la tierra entregada produjeron la constitución de un vecindario de pequeños y medianos productores-propietarios rurales. Estas donaciones fueron "condicionadas" porque la obtención de los títulos legales estaba sujeta al cumplimiento del poblamiento efectivo, la puesta en producción agraria y la defensa local a partir del servicio miliciano según los decretos de 1829 y 1832¹, que permitieron estos repartos de tierras.

Los terrenos cedidos fueron rápidamente ocupados y puestos en producción por distintos tipos de productores/ propietarios rurales que, en algunos casos, también estaban dedicados a actividades comerciales, fomentando la migración y el establecimiento de pobladores criollos y extranjeros en la región (LANTERI, 2002; BANZATO; LANTERI, 2007). Los datos demográficos indican una población "blanca" en constante crecimiento, aunque el más pronunciado se produjo entre 1830-1850, acompañando el proceso de ocupación de las suertes. La tasa de crecimiento porcentual anual indica un 4,1\% entre 1838 y 1854, con escasa variación del espacio ocupado en

1 Registro Oficial del Gobierno de Buenos Aires, decreto del 19 de septiembre de 1829 y del 9 de junio de 1832. Buenos Aires: Imprenta del Estado, pp. 17-21. 
ese período. ${ }^{2}$ Para la etapa 1854-1869 el guarismo disminuye a 1,33\%, lo que refiere que el mayor porcentaje de población se estableció en Azul durante el período rosista. ${ }^{3}$

Mediante las donaciones de las suertes y las concesiones enfitéuticas ${ }^{4}$, la extensión en principio ocupada por el Estado provincial en esta zona no sólo se vio afianzada sino ampliada con creces, pasando de 169.506 has en el decenio de 1820 a 757.088 has en el de 1830, cifra que se incrementó en la década siguiente y tuvo una disminución considerable en la de 1850, debido a las invasiones indígenas que se abatieron sobre la región y a la entrega de terrenos a la tribu catrielera como se verá más adelante (LANTERI, 2005, 2007).

Pero los vecinos criollos que se establecieron en la región no estaban solos. Antes de la fundación del pueblo de Azul y coexistiendo con los pocos enfiteutas que se habían arriesgado a asentarse allí, habitaban algunos grupos indígenas que, mediante negociaciones diplomáticas iniciadas con el gobierno bonaerense en el año 1827, habían acordado instalarse dentro del espacio provincial. Ahí se ubicaron, en un primer momento, los indios del cacique transcordillerano Venancio Coyhuepán - quien en 1828 integró la expedición fundadora del fuerte de Bahía Blanca donde se estableció posteriormente- y los grupos que respondían a los jefes pampas J uan Catriel y Juan Manuel Cachul. Estos últimos tenían una larga relación con J uan Manuel de Rosas y habían llegado a habitar en su establecimiento "Los Cerrillos” en Monte (RATTO, 1994a; LANTERI, 2005).

Al asumir la gobernación de la provincia, Rosas mantuvo y profundizó la política indígena de reducciones incorporándose más pobladores indios a la campaña bonaerense. Esta política consistió en una contraprestación de bienes y servicios mediante la cual los indígenas recibían entregas periódicas de ganado (equino y vacuno), vestimenta y artículos de consumo denominados "vicios de costumbre" (yerba, azúcar, aguardiente, tabaco, sal, etc.) y debían formar contingentes auxiliares en las milicias provinciales, así como cumplir otras tareas (chasques, trabajo rural, etc.). A los "indios amigos"5 que aceptaron estas condiciones se les asignaron tierras en los

2 Los cambios territoriales más significativos fueron encontrados en el decenio de 1830 y luego de la caída del rosismo en el año 1852 (LANTERI, 2005, 2007).

3 De hecho, la tasa registrada durante 1869-1895, en una coyuntura bien diferente signada por la entrada masiva del flujo inmigratorio internacional, fue del $4,6 \%$ anual, bastante similar a la de la primera mitad del siglo.

4 Modalidad empleada por el Estado provincial desde el gobierno de Martín Rodríguez (1820-1824), con reformulaciones durante el rosismo, que otorgaba el usufructo de amplias extensiones de tierras públicas a particulares a cambio de un canon bajo (INFESTA, 2003).

${ }^{5}$ Entendemos por tales a los grupos nativos que fueron reducidos en territorio provincial bajo control militar del gobierno provincial y que cumplían diversas funciones - chasques, peones rurales- que con el tiempo se fueron concentrando en el servicio miliciano. Para más datos ver Ratto (1994a, 1994b). 
partidos más fronterizos para que establecieran sus tolderías, pero durante todo el período rosista eso no implicó ni la permanencia estable de los grupos ni la transferencia de terrenos a éstos (RATTO, 2003a; LANTERI; PEDROTTA, 2009). Es dable destacar aquí la diferente noción sobre el espacio y el territorio que los grupos nativos y los actores estatales tuvieron, pues mientras para los primeros constituyó una dimensión cultural cargada de significación cosmológica no aprehensible mediante los cánones cartesianos ni en términos de propiedad privada individual, para los segundos formó parte del proceso de construcción del Estado-Nación durante la centuria, involucrando una intencionalidad de control sobre los recursos, objetos y personas dentro de la soberanía oficial. No obstante, la noción de territorialidad indígena no fue inmutable, sino que fue redefiniéndose al calor de las diversas coyunturas históricas e interétnicas, así como también la noción de propiedad privada "occidental" estuvo mediatizada por tradiciones culturales y prácticas campesinas de antiguo arraigo en la campaña de Buenos Aires (LANTERI; PEDROTTA, 2009).

$\mathrm{Si}$ bien se establecieron asentamientos indígenas en las cercanías de casi todos los fuertes fronterizos - Federación, 25 de Mayo, Bahía Blanca, Patagones- la región de Azul y Tapalqué constituyó, sin lugar a dudas, el centro de los mismos. Tapalqué tenía 2.638 aborígenes asentados en 1832 (899 indios de pelea, 970 mujeres y 769 niños); 2.650 en 1836 y 1.833 hacia 1840 (655 indios de pelea, 658 mujeres y 520 niños), luego de malones previos que habían diezmado a la población de "indios amigos". ${ }^{6}$ Según el censo provincial efectuado en 1854, Tapalqué albergaba "6.000 indios" frente a una población criolla mucho más reducida (515 habitantes), mientras el partido colindante de Azul presentaba 5.912 personas -aunque la fuente no especifica su composición-. ${ }^{7}$ Con todo, según el primer censo nacional de 1869, la población de Azul era de 7.209, y si bien diversas fuentes aluden a la presencia de miles de aborígenes en Tapalqué, la población "blanca" había crecido de forma notable, debido probablemente a migraciones internas, externas y al propio crecimiento vegetativo. Los 2.394 habitantes estaban consignados en su mayoría como "argentinos" por sobre otras nacionalidades americanas y europeas, con el 89,4\%, es decir, 365\% más que en 1854, en un lapso de

\footnotetext{
${ }^{6}$ Para 1832 se cuenta además con datos sobre la distribución por caciques de 2.626 personas sobre esas 2.638. Catriel encabezaba a 1.734 individuos (519 hombres de pelea, 672 mujeres y 543 niños); Cachul comandaba a 433 (149 hombres de pelea, 158 mujeres y 126 niños); mientras Francaman nucleaba a 188, Reylef a 140, Cayupan a 58, Quiñigual a 67 y los caciquillos Painen y Llanqueman sólo a 6 personas, (RATTO, 2003b, p. 129).

7 Primer Censo de la República Argentina, Verificado en los días 15, 1617 de Setiembre de 1869. Bajo la dirección de Diego de la Fuente, Superintendente del Censo. Buenos Aires: Imprenta del Porvenir, 1872, pp. 18. En los padrones de la campaña de 1836 y 1838 Tapalqué sólo registra información para el primer año, contando con 7 cabezas de unidad censal con 31 personas, algunos de aquellos con unidades en Azul. Archivo General de la Nación, Sala X, Legajos 25-2-4 y 25-6-2 (LANTERI, 2008b).
} 
sólo quince años, evidenciando el poblamiento "blanco" más tardío en el marco de la abundante presencia aborigen de principios de siglo. La relación de masculinidad en Tapalqué era más alta que la de Azul, de 138,4/100; representando el 1,7\% del total de población de la campaña sur, y el 7\% del total de esta región entre Azul y Tapalqué en conjunto (LANTERI, 2008b).

A partir del segundo gobierno de Rosas y con mayor énfasis desde fines de la década de 1830, la existencia de unidades milicianas indígenas se convirtió en un rasgo distintivo del ejército provincial. Y aunque todos los fuertes contaban con indios de pelea, la concentración de población ya mencionada llevó a que fuera en la región de Azul-Tapalqué donde esta participación cobró mayor relieve. Allí, tanto los indios "amigos" como los pequeños-medianos propietarios participaron activamente en la legitimación y defensa del territorio fronterizo y de la federación rosista, a través de su intervención en las elecciones anuales para representantes de la Sala provincial y del servicio armado en diversos conflictos, como los malones de 1836 y 1837, la rebelión de los "Libres del Sud" en 1839, e incluso hasta la misma batalla de Caseros, que culminó con el gobierno de Rosas en febrero de 1852 (RATTO, 2003b; LANTERI, 2008a, 2008b, 2011; LANTERI; SANTILLI, 2010).

La concentración poblacional indígena en Azul-Tapalqué se ha visto confirmada por estudios arqueológicos que refieren a la importancia del asentamiento de las tribus de "indios amigos" inclusive hasta el tercer tercio de la centuria. Las principales evidencias proceden de dos sitios arqueológicos localizados a la vera del arroyo de Nievas, en cuyas tierras fueron establecidos los grupos indígenas a partir de 1856, cuando se revitalizaron las paces que habían concluido luego de la caída de Rosas con la reestructuración del "negocio pacífico" por el Estado de Buenos Aires (ver apartado siguiente). La información aportada por el registro arqueológico, los análisis del material lítico, vítreo y óseo, los estudios edafológicos, así como la existencia de diversas estructuras de piedra, indican la permanencia estable de estas parcialidades, el desarrollo de actividades productivas y comerciales diversas, su inclusión en redes complejas de intercambio mercantil locales, regionales y extra-regionales, patrones de asentamiento sedentarios en sitios con estructuras habitacionales domésticas, corrales, puestos de vigilia y defensa territorial, entre otros (PEDROTTA, 2005; FERRER, PEDROTTA, 2006). 


\section{La Frontera Sur en el Período Separatista}

En febrero de 1852 la batalla de Caseros puso fin al gobierno de Rosas. El vencedor, J usto J osé de Urquiza, gobernador de Entre Ríos, intentó llevar adelante el proyecto de organización nacional pero los porteños no apoyaron la idea de una futura Confederación con predominio entrerriano (SAENZ QUESADA, 1979). La revolución del 11 de septiembre expresó este rechazo y derivó en la separación de Buenos Aires del resto de la Confederación. Pero poco después, el 1 de diciembre, un movimiento de base rural dirigido por el coronel Lagos desafió a las nuevas autoridades porteñas y a su proyecto separatista. El 21 de enero las fuerzas opositoras se encontraron en la batalla de San Gregorio pero la victoria confederacional no implicó la reintegración de Buenos Aires a la Confederación. ${ }^{8}$ A pesar de la misma y del sitio que experimentó la ciudad por espacio de seis meses, el movimiento separatista triunfó y los dos Estados se mantuvieron separados por cerca de 10 años. Entre 1853 y 1861, el Estado de Buenos Aires tuvo que hacer frente a una constante hostilidad tanto por parte de los confederales que intentaron invadir en varias oportunidades la provincia (SCOBIE, 1964), como por parte de grupos indígenas de la pampa que protagonizaron fuertes ataques a la frontera, en ocasiones, incentivados por los primeros y en otros, apoyados por grupos nativos ubicados en el interior del territorio provincial. La sublevación de los llamados "indios amigos" no era una novedad y ya en el período rosista se habían registrado situaciones de esta naturaleza. Sin embargo, vale la pena detenerse en los motivos que llevaron en este momento al levantamiento de los indios reducidos, ya que se trata precisamente de las tribus catrieleras ubicadas en el espacio objeto de este estudio.

Al finalizar el sitio de Buenos Aires, en junio de 1853, la campaña sur se encontraba -según los informes de los comandantes de los fuertes- en completa calma. En octubre, el comandante de Azul, Rosas y Belgrano, informaba que "todos los caciques amigos de Tapalqué y Salinas han mandado a este punto a saludar al infrascripto manifestando su contento por la paz que goza la provincia”.

Pero esta paz duraría poco. En el quiebre de la relación interétnica tuvo un papel fundamental el cambio en el elenco de personas encargadas de los asuntos de frontera. En octubre de 1853 Rosas y Belgrano renunció al juzgado de paz de Azul, con lo que los "indios amigos" perdieron a su principal referente, ya que éste se había desempeñado desde hacía más de una década en la región y había logrado movilizar un importante cuerpo indígena para enfrentar a las tropas de Lagos en la batalla de San

${ }^{8}$ En estos enfrentamientos, siguiendo una tradición instalada durante el rosismo, se registró la participación de milicias indígenas. 
Gregorio. En enero de 1854 su reemplazante, Ezequiel Martínez, encabezó una solicitud de los vecinos principales para que el pueblo de Tapalqué fuera trasladado unas ocho leguas al sudoeste, a las nacientes del arroyo homónimo, sobre un territorio que estaba ocupado por las tolderías indígenas. El gobierno aceptó el pedido previa confección de planos y autorizó la expropiación de terrenos para hacer el traslado (CAPDEVILA, 1963, p. 127). Este proyecto de avance sobre tierras ocupadas desde hacía décadas por indígenas se sumó a otras medidas que mostraban claramente que el signo del nuevo gobierno liberal establecido en Buenos Aires era contrario a mantener el trato pacífico. Así, se interrumpió el comercio interétnico y se intentó uniformar la "Caja de Indios", partida presupuestaria que incluía las raciones enviadas a las tolderías. Estas cajas eran manejadas por los comandantes de frontera y variaban según la cantidad de bocas que integraban las diferentes tribus y la particular relación que cada cacique había obtenido con el gobierno provincial. El intento de éste último por equipararla al "rancho" militar, que era una medida fija de provisiones que recibían los soldados, implicaba un quiebre importante en las relaciones con los caciques, ya que terminaba con el trato personal y el abastecimiento diferencial que habían logrado los principales caciques en la frontera sur (BELLONI, 2010).

Estas transformaciones en la política de frontera tuvieron su punto álgido en 1855. En enero se nombró Ministro de Guerra a Bartolomé Mitre, quien decidió poner en práctica el plan que venía elaborando para asegurar la campaña: reorganización del ejército de línea y fundación de colonias agrícola-militares para contener a los indígenas y poblar el "desierto". De esa época data el establecimiento de la Colonia Agrícola Militar de la Legión Italiana en el Sauce Chico, pocas leguas al norte de Bahía Blanca, y el traslado efectivo del cantón de Tapalqué.

En febrero los informes desde Azul mencionaban la existencia de un "enjambre de indios por las cercanías y terror por parte de los vecinos de que éstos efectivicen un ataque". Los rumores que circulaban señalaban que el cacique huilliche

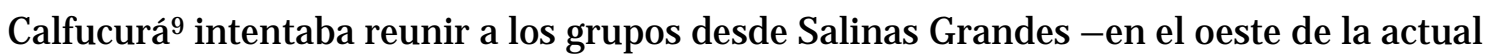
provincia de Buenos Aires- hasta el río Negro para invadir la campaña y, si bien no se mencionaba a los indios de Tapalqué, algunas actitudes de éstos hacían presumir que también habían sido convocados. ${ }^{10}$ Pocos días después una inmensa invasión avanzó

\footnotetext{
9 Procedente de la región de Llaima, el cacique se había instalado a inicios de la década de 1840 en la región de Salinas Grandes. Diez años después era, sin lugar a dudas, el líder que podía convocar la mayor cantidad de seguidores para realizar campañas de apropiación de ganado, ver De J ong y Ratto (2008).

10 Archivo del General Mitre (1912), (en adelante AM) Tomo XV, p. 196-197.
} 
por Azul y Tandil llevándose 60.000 vacunos y 150 cautivos. ${ }^{11}$ En el mes de mayo la tensión alcanzó su pico de mayor intensidad cuando los indígenas resistieron por la fuerza el intento de fundar el nuevo pueblo de Tapalqué, apresando al juez de paz de Azul, Ezequiel Martínez, junto a otros vecinos y matando al policía y al capataz que formaban parte del grupo (LANTERI; PEDROTTA, 2009). ${ }^{12}$ Debido a la gravedad de los acontecimientos, el ministro Bartolomé Mitre decidió crear en Azul el Cuartel General de Operaciones y uniendo las tropas locales con las que comandaba Laureano Díaz, jefe de la Comandancia del Centro, se decidió un ataque a las tolderías de Catriel y Cachul quienes, a partir de ese momento, se integraron a los grupos maloneros. La ola de violencia no hizo más que incrementarse y el gobierno reaccionó movilizando tropas hacia el sur. A fines de mayo las fuerzas provinciales iniciaron una serie de ofensivas militares que culminaron en derrotas, lo que motivó que el mismo gobernador, Pastor Obligado, se trasladara a la frontera para organizar una nueva ofensiva militar con la que se esperaba acabar con los ataques indígenas. ${ }^{13}$ Empero, este último intento tampoco fue exitoso y el gobierno decidió cambiar radicalmente su política agresiva por la vía diplomática.

En octubre de 1856, al cabo de cuatro meses de negociaciones, el Gral. Escalada en representación del Estado de Buenos Aires, firmó un tratado con los caciques Juan "segundo" Catriel14 y Juan Cachul. De los veintiún puntos que conformaron dicho tratado, queremos destacar: 1) el mutuo compromiso para mantener la paz y ayudarse en caso de ataques; 2) el reconocimiento de un territorio de 20 leguas cuadradas (unas 54.000 has) situadas al oeste del arroyo Tapalqué -sus límites debían ser establecidos más adelante donde las tribus debían vivir "pacíficamente ejerciendo su industria y cultivando la tierra"; 3) el canje de cautivas; 4) la reasignación trimestral de raciones comestibles (yeguas, harina, maíz, bebidas alcohólicas, entre otros productos) y "vicios de costumbre" (yerba, azúcar, tabaco y papel); 5) el restablecimiento del comercio y de las relaciones laborales y 6) los nombramientos militares para los indígenas con sus remuneraciones mensuales respectivas (texto completo del tratado en LEVAGGI, 2000, p. 298-300).

Sin embargo, el deslinde proyectado nunca se realizó y subsistió un desacuerdo básico entre las autoridades gubernamentales y los caciques sobre la localización de las tierras indígenas. En efecto, Bartolomé Mitre pretendía que los campos para "correrías y boleadas" estuvieran alejados entre veinte y treinta leguas del

11 AM, Tomo XV, p. 98.

12 AM, Tomo XV, p. 107-108 y 208-209.

13 AM. Tomo XV, p. 81.

14 Que había sucedido a su padre como cacique principal en 1848. 
territorio poblado por los criollos y que dejaran libre "todo lo que comprende desde los caminos de Tandil a Bahía Blanca y Patagones hasta la costa del mar". ${ }^{15}$ En contraste, los caciques consideraban que, mediante el citado tratado, el gobierno les había reconocido la propiedad de las tierras situadas inmediatamente al oeste de las sierras Bayas (LANTERI; PEDROTTA, 2009). No obstante este desacuendo sobre la demarcación definitiva del territorio en la zona rural, a partir de la firma del tratado de 1856 la agrupación catrielera se reinstaló en los campos de los arroyos de Nievas y Tapalqué, incrementándose el dinero y las raciones que recibía, así como sus actividades comerciales en Azul (BARROS, 1975; DURAN, 2002). Su retorno a las tierras cercanas a Azul fue acompañado en los años inmediatos por las tribus pampas de Lucio López y su hijo Chipitruz, Calfuquir, Cholaylaf y Comihuala, que al desprenderse de la Confederación Indígena de Calfucurá, se ubicaron en las tierras de Tapalqué (HUX, 1993). Poco tiempo después, el cacique Catriel concedió finalmente una parte de esos terrenos para que fuera construido el nuevo fuerte y pueblo de Tapalqué, actual ciudad de Olavarría (ARENA; CORTES; VALVERDE, 1967).

Como se ha visto, este período de conmoción política e interétnica recién logró estabilizarse hacia los últimos años de la década de 1850. En materia de legislación territorial, con la sanción de la ley de arrendamientos rurales y las ventas públicas durante 1857-1876, se comenzó a revisar y organizar la situación jurídica de los tenedores precarios de tierras fiscales en la provincia de Buenos Aires, así como aquellas diligencias que había dejado irresuelta la legislación rosista y la etapa inmediatamente posterior. Esta cuestión era de central importancia, pues no sólo se vinculaba con el control del espacio austral y los recursos para articular al ciclo del ovino en marcha orientado al eje atlántico, sino también con el propio modelo de sociedad que los liberales porteños querían construir, basado en la ocupación y puesta en producción efectiva de los usufructuantes por sobre el pago de cánones al gobierno y en la propiedad privada plena al estilo norteamericano (VALENCIA, 2005). Los arrendamientos rurales y también mayormente las ventas públicas, lejos de fomentar la concentración territorial como en el caso de la enfiteusis, ampliaron la ocupación productiva criolla en la provincia durante la segunda mitad del siglo, quedando aquélla dividida en dos partes a través de la línea de frontera establecida en 1858, con normativas diferentes para los campos situados al interior y al exterior, presentando éstos últimos precios menores debido a la "amenaza indígena" -según estipularon los legisladores coetáneos- (VALENCIA, 2005).

15 Carta de Bartolomé Mitre del 15 de noviembre de 1856, en Levaggi (2000, p. 302). 
En lo referido propiamente al área de estudio, el impacto de la pequeña y mediana propiedad rural desde el inicio del proceso colonizador regional se mantuvo inclusive durante 1850-1860, cuando el territorio criollo presentó una disminución general de aproximadamente 168.000 has por los malones indígenas de 1853-1855, que ocasionaron el despoblamiento de algunas suertes y también por la ocupación de parte de los terrenos por la tribu catrielera según el acuerdo mencionado de 1856.16 En este decenio, el 87,5\% de los tenedores de Azul poseía el 53,3\% de las tierras en el segmento 0-2.699 has, mientras el 1,4\% concentraba el 19,2\% en superficies mayores a las 29.700 has, creciendo el número de los medianos propietarios, especialmente en la franja 2.700-8.099 has, debido a la fragmentación de las grandes propiedades consolidadas en 1830's (LANTERI, 2007).

Empero, si bien la pequeña-mediana tenencia fue medular, los donatarios fueron propietarios de hecho hasta fines del decenio de 1850, pues recién en plena etapa de revisión rosista pudieron tener derecho al acceso formal pleno de sus tierras a partir de la sanción de diversas leyes, como la de arrendamientos rurales de 1857 que comprendía a las suertes de estancia. En tanto, la ley dictada el 21 de octubre del mismo año permitió el acceso legal de los campos, en caso de que los pobladores hubiesen cumplido con las condiciones del decreto de 1829 (INFESTA, 2003; VALENCIA, 2005). Estas normativas permitieron el acceso pleno de las suertes cedidas desde 1830, en un proceso de escrituración legal que comenzó entonces pero continuó mayormente en las décadas siguientes (LANTERI, 2011).

En suma, pese a los importantes cambios institucionales e interétnicos sucedidos a partir de la caída de Rosas en 1852, la presencia indígena y campesina in situ continuó siendo central y amparada incluso por las políticas oficiales. Sin embargo, las formas de acceso de las poblaciones indígenas y no indígenas a la tierra - por reconocimiento de territorios a partir de acuerdos diplomáticos, en el primer caso; por operaciones de venta y arrendamiento, en el segundo- fueron totalmente diferentes. Veamos ahora lo sucedido hasta el tercer cuarto de la centuria.

16 Con todo, la mayoría de las suertes estaban pobladas hacia 1859, habiendo 108 "taperas" debido a las razones expuestas, embargos rosistas, etc. Cornell, J uan, "Informe dirigido al Sor Ministro de Gobierno en el que se da cuenta haber desempeñado Don Juan Cornell la comisión de que fue encargado para el Partido Arroyo Azul", 1859, Archivo Histórico de la Dirección de Geodesia y Catastro de la Provincia de Buenos Aires (LANTERI, 2008b). 


\section{El Estado Unificado Hasta 1875}

Entre 1862, año en que Bartolomé Mitre asume como presidente del Estado nacional unificado y 1879, en que se inician las campañas militares dirigidas a la ocupación de las Pampas y la Patagonia (conocidas como la "Conquista del Desierto"), la política estatal hacia los indígenas se basó en la oferta sistemática de tratados de paz a una gran cantidad de caciques de estas regiones. Esta política de tratados de paz reflotó en sus términos básicos el "negocio pacífico de indios" sostenido por Rosas y antes descripto, fortaleciendo vínculos de abastecimiento en raciones y sueldos con algunas agrupaciones y favoreciendo la instalación de otras como "indios amigos" en la frontera, especialmente en los sectores oeste y sur de la provincia de Buenos Aires. Paralelamente, el Estado fue definiendo a nivel legislativo ${ }^{17} \mathrm{y}$ organizativo los objetivos de ocupación de los territorios indígenas y realizando, entre los años 1864 y 1876, avances parciales de la línea de fronteras. De esta manera, la práctica diplomática se fue consolidando como instrumento de control de la resistencia indígena al avance territorial del Estado. La estabilización de las relaciones comerciales y de abastecimiento en raciones con algunos sectores del campo indígena convivió con una dinámica fluctuante de ruptura de relaciones y recomposición de tratados con otros sectores, principalmente ranqueles y salineros, más directamente afectados por el avance fronterizo (DE J ONG, 2007).

Es importante tener en cuenta este panorama al enfocar las experiencias de asentamiento e incorporación de los "indios amigos" en las distintas jurisdicciones del territorio de la provincia de Buenos Aires a lo largo de las décadas de 1860 y 1870. Parte de las tribus amigas incorporadas ya en la etapa rosista se habían mantenido en sus antiguos lugares de asentamiento, como las del cacique Francisco Ancalao, en las cercanías de Bahía Blanca, la de los hermanos Manuel y Francisco Rondeau, en 25 de Mayo y la de los caciques Pedro Melinao y Raylef, en la Barrancosa. A su vez, y como vimos, el ofrecimiento de un tratado de paz a Juan "segundo" Catriel en 1856 marca el retorno de los catrieleros a la zona de Azul, acompañados - como señalamos más arriba- por otros contingentes de caciques, entre los que se encontraban Lucio López, su hijo Chipitruz, Calfuquir y Comihuala. Paralelamente, desde la jurisdicción de Patagones, con un tratado firmado en 1857 se recomponían los vínculos con el cacique Yanquetruz, a quien sucederían su primo Chingoleo y luego Miguel Linares, como representante de los "indios amigos" del área.

17 En 1867 el Congreso Nacional sancionó la Ley 215 que ordenaba la ocupación de los ríos Negro y Neuquén como línea de frontera Sud contra los indios, autorizando al Poder Ejecutivo a hacer uso del crédito nacional para tal objetivo y definiendo la empresa como de carácter básicamente militar. 
Pero la década de 1860 también significó la incorporación de numerosas tribus a distintos sectores de la frontera. Diversos caciques que habían participado de la Confederación Indígena liderada por Calfucurá y que habían protagonizado los malones de la década anterior, fueron gestionando tratados individuales con el gobierno mediante los cuales se acordó su asentamiento y su incorporación al régimen de "indios amigos". En el sector oeste de la frontera, para 1862 se instaló, en los campos cercanos a Bragado y 9 de J ulio, la tribu del cacique borogano Ignacio Coliqueo, quien fue convirtiéndose en el principal referente indígena entre los "indios amigos" locales. Muchos otros caciques con sus tribus negociaron en los años siguientes su asentamiento en los sectores sur y costa sur de la frontera, especialmente en la zonas de Tapalqué y Bahía Blanca. Entre ellos pueden citarse los caciques Millacurá (1858) en Azul, Manuel Grande y Quentriel (1866) en la zona de Tapalqué, así como a Cañumil, Guayquil e Ignacio (1865) en las cercanías de Bahía Blanca (DE J ONG, 2007).

Las trayectorias de estos grupos fueron diferentes, ya que su situación evolucionó en función de un conjunto de variables, entre las que se pueden contar la ubicación geopolítica de las jurisdicciones fronterizas, las relaciones comerciales y diplomáticas desarrolladas por sus autoridades con distintos sectores del mapa político indígena así como las alianzas mantenidas por los caciques amigos con los grupos de "tierra adentro". Estos factores imprimieron una dinámica muy distinta a la participación de las tribus amigas en los vínculos diplomáticos y de confrontación bélica que se alternaron a lo largo de estas décadas, diferenciando también la forma en que se insertaron en la administración fronteriza (DE J ONG et al., 2009).

En tal sentido, la distancia política que mantuvo el cacique Ignacio Coliqueo respecto de los salineros de Calfucurá -en parte como resultado de antiguas oposiciones políticas $^{18}$ - y el apoyo de sus lanceros a las fuerzas de la frontera oeste acompañaron durante este período sus solicitudes de tierras en propiedad así como de la acción religiosa y educativa entre los miembros de su tribu. El gobierno nacional, interesado en disminuir las alianzas de quien hasta hacía pocos años había dirigido la Confederación Indígena, apoyó probablemente con mayor énfasis la concesión de tierras a las tribus de Coliqueo y a las de otros caciques emparentados con éste, asentados desde la etapa rosista en el oeste bonaerense. De este modo, en la década de 1860, una vez unificado el Estado, el congreso nacional otorgó tierras en propiedad a

18 La llegada de Calfucurá a Salinas Grandes, a mediados de la década de 1830, se asentó en la derrota de los grupos boroganos de Rondeau y Melín, entre los que se encontraba Coliqueo. Esta confrontación pudo encontrar continuidad, a su vez, con líneas de competencia política previas de estas agrupaciones en el territorio chileno, fomentadas por la participación en bandos opuestos de estos grupos en las guerras independentistas de Chile (RATTO, 1996). 
Ancalao en Bahía Blanca, a Raylef y Melinao en Bragado, a Coliqueo en 9 de J ulio, a los hermanos Rondeau en 25 de Mayo y a Raninqueo - que se había desprendido de la tribu de Coliqueo- en La Verde, en los alrededores de Bolívar (FISCHMAN; HERNANDEZ, 1993; DE J ONG, 2007). ${ }^{19}$ Estos otorgamientos tomaron la forma de la concesión de tierras al "cacique y su tribu", en extensiones que variaron entre dos y seis leguas cuadradas, estipulándose la prohibición de su venta por un plazo no menor a diez años y postergándose la reglamentación sobre su subdivisión entre las familias indígenas por considerárselas ajenas a sus costumbres. ${ }^{20}$

Es probable que la situación creada por la Guerra del Paraguay - que obligó a destinar la mayor parte del ejército al frente internacional, dejando desprotegidas las fronteras- haya favorecido las concesiones realizadas entre 1863 y 1869. Estas decisiones se hallaban comprendidas, al mismo tiempo, en una política que favorecía el poblamiento por fuera de la línea de fronteras ${ }^{21}$ y coincidían con diversos proyectos que alentaban la formación de colonias compuestas por población indígena e inmigrante (HALPERIN DONGHI, 2005). Cabe destacar, sin embargo, que la provincia de Buenos Aires no presentó una colonización tan dirigida desde el Estado como la que tuvieron otras de la región pampeana, como Santa Fe o Entre Ríos, ya que de forma paralela al establecimiento de inmigrantes europeos -típicos de esta coyuntura- y a las cesiones indígenas, coexistía una gran diversidad de productores y propietarios rurales, ya sea estancieros mixtos de mayor o menor envergadura, arrendatarios, aparceros, puesteros, etc., autosuficientes pero también vinculados con mercados locales y externos (ZEBERIO, 1999).

Sin embargo, no tuvieron igual éxito las solicitudes de tierras efectuadas por los caciques Chipitruz y Manuel Grande, asentados en Tapalqué, y de Quentriel, en las cercanías de Blanca Grande, a pesar de reiteradas solicitudes al gobierno durante la década de 1860. En este sentido, la política estatal sobre los “indios amigos" no parece

19 Estas concesiones no se hicieron sin confrontaciones y debates en las cámaras legislativas, en las que las propuestas de concesión encontraron la oposición de legisladores que sostenían que los "indios amigos" eran los principales causantes de los robos en la frontera. Debate en la Cámara de Diputados de la provincia de Buenos Aires de la Ley no 611 de concesión de tierras a Raninqueo y su Tribu (Informe de la Comisión Investigadora de las Tierras de Coliqueo, 1940, p. 420-423).

20 Incorporar la obligación de subdividir las tierras en propiedad individual a las leyes de concesión, según algunos diputados, era la única manera de conducir a los indígenas a la adopción de costumbres "civilizadas". Pero para otros, ello implicaba "introducir una legislación que no conocen ni aceptarían", aumentando a su vez el riesgo de que la posesión individual favoreciera la rápida reventa de las tierras adjudicadas, revirtiendo el proceso de asentamiento aborigen y conformando una nueva fuente de conflictos. "Sanción y debate de las leyes de 1866 y 1868" (Informe..., 1940, p. 89-110).

21 Entre 1858 y 1876 se pusieron en arriendo un total de más de cinco millones de hectáreas, de las cuales 3.861.913 - el 77\%- correspondieron a contratos en el exterior de la frontera, que no pagarían el arriendo hasta tanto el avance de la línea no los incluyera (BARSKY; DJ ENDEREDJ IAN, 2003). 
haberse orientado en todos los casos a reconocer la propiedad de sus asentamientos y consolidar esta ocupación. En 1866, según un informe del Teniente Coronel a cargo de las comisiones de indios, J uan Cornell, los caciques se quejaban de que "desde Bragado a Bahía Blanca dan en concesión tierras en arrendamiento o compra sobre las mismas extensiones de campos que ellos ocupan desde hace tantos años, y las han solicitado en propiedad. Piden que se suspendan dichas concesiones". ${ }^{22}$

En este sentido, las localidades de Azul y Tapalqué representan un espacio singular y contrastante con otros sectores de la provincia, en tanto la importante población indígena que tenía continuidad en esta área desde la etapa rosista encontró dificultades para obtener la concesión en propiedad plena solicitada al Estado por algunos grupos de "indios amigos". Probablemente por constituir la zona de abastecimiento y comercio con los salineros, así como por mantener éstos vínculos políticos, comerciales y de parentesco con catrieleros y tapalqueneros, las relaciones entre los "indios amigos" de Azul y Tapalqué con las autoridades civiles y militares de la jurisdicción fueron atravesadas por numerosos conflictos políticos. ${ }^{23}$ Además, debe recordarse el interés central que esta zona de la frontera sur representaba para la elite dirigente y propietaria, en contraste con el norte o el oeste provincial.

Si bien ya podemos reconocer la existencia, por parte de las autoridades militares, de una práctica destinada a oponer a caciques de Azul y Tapalqué desde fines de la década de 1850 y principios de 1860 (DE JONG, 2008), es en el siguiente decenio cuando dichos conflictos se agudizan, con un impacto directo en la territorialidad de estos grupos. En 1870, una vez finalizada la Guerra del Paraguay, desde la Comandancia de Fronteras de Azul se alentó la firma de un nuevo tratado con el cacique Cipriano Catriel24, por el cual se lo nombró “J efe principal” de las tribus amigas de Azul y Tapalqué, convocándolo a reprimir a aquellos que no se subordinaran a su autoridad. Esta represión se concretó al año siguiente en el episodio conocido como "Laguna de Burgos", ataque que ocasionó el desplazamiento de las tribus de Chipitruz, Manuel Grande, Ramón López, Varela y otros caciques que no volvieron a Tapalqué. 25

22 Archivo del Estado Mayor, Nro. 9085, 17de abril de 1866, en Hux (1993, p.152).

${ }^{23}$ Entre ellos podemos considerar los enfrentamientos entre catrieleros y tapalqueneros, la significativa participación de los lanceros de Catriel en la batalla de San Carlos, contra las fuerzas confederadas de Calfucurá y la Revolución Mitrista de 1874, en el marco de la cual Cipriano Catriel es destituido y muerto por un sector de su tribu liderado por sus hermanos J uan J osé y Marcelino Catriel.

24 Hijo de Juan "segundo Catriel", a quien sucedió a fines de 1866.

${ }^{25}$ Estos se trasladaron al sector oeste de la frontera, sufriendo posteriormente la prisión en la isla Martín García. Encontramos unos años después a Manuel Grande solicitando seis leguas cuadradas de tierra por la zona de La Verde, en el oeste bonaerense (Carta de Manuel Grande al Arzobispo Federico Aneiros, 5 de agosto de 1876, en (COPELLO, 1944, p. 150). Por otra parte, sabemos que Chipitruz se instaló en Sierra Chica, partido de Olavarría, al salir de Martín García, pues sus tierras habían pasado a manos "cristianas" (HUX, 1993). 
En 1874 el cacique Cipriano Catriel fue destituido y muerto por sus hermanos J uan J osé y Marcelino, quienes representaron una posición más intransigente ante el gobierno. Al mismo tiempo, el gobierno de Avellaneda, con Adolfo Alsina como Ministro de Guerra, definió desde 1875 un conjunto de medidas de carácter ofensivo, que terminaron por concretarse con la ocupación de Italóo, Puán, Guaminí y Carhué, y la construcción de la "zanja de Alsina” para impedir el paso de los arreos indígenas. Este plan implicó para los catrieleros la oferta, a través de un nuevo tratado, de trasladar su asentamiento hasta la nueva frontera, además de su incorporación formal a las fuerzas militares y el uso de uniforme. Aunque este tratado fue firmado, el levantamiento de los catrieleros a los pocos días demostró el rechazo a estas medidas. En diciembre de 1875 gran parte de la tribu abandonó para siempre sus tierras en Azul y se unió a las fuerzas de Namuncurá, Pincén, Baigorrita y otros grupos provenientes de Neuquén y Chile, participando en un ataque combinado sobre el sur bonaerense (HUX, 1993).

Es necesario considerar, en relación al tema analizado, las formas en que los caciques y sus seguidores percibían sus derechos sobre la tierra ocupada y las modalidades bajo las cuales podían llegar a negociar con las autoridades estatales su relación con la tierra. No registramos, en principio, pedidos formales contemporáneos de concesión de tierras similares a los de Coliqueo, Melinao, Rondeau o Ancalao de parte de los catrieleros. Según el Intendente de Indios Santiago Avendaño, la pretensión de medir y subdividir los campos de este último grupo era un tema delicado y podía provocar grandes resistencias, por lo que requería un trabajo de persuasión y ejemplo progresivos. ${ }^{26}$ De hecho, hemos registrado la oposición manifiesta de este grupo a las mensuras de los agrimensores comisionados para las suertes del Azul en su territorio en los años 1863 y 1872 (LANTERI, PEDROTTA, 2009).

En esta compleja y dinámica coyuntura son inteligibles las operaciones de tierras fiscales que efectuaron en la zona de estudio. Es dable señalar que Tapalqué registró más transacciones que Azul durante el segundo tramo del siglo, tanto en cantidad de transferencias como en el volumen implicado en los arrendamientos y las ventas, pese a que otros partidos australes superaron a ambos. Si, por ejemplo, Azul presentó 185.749 has transferidas en arrendamiento mediante 16 operaciones, Tapalqué implicó un monto de 237.466 has a través de 26 durante el lapso 1858-76, y si el primero involucró 25.859 has cedidas mediante 6 transacciones según la ley de ventas de tierras públicas de 1871, Tapalqué tuvo 408.552 has a través de 59 (VALENCIA, 2005, p.240-241 y 318-319). Esta situación se explica en el marco de la

${ }^{26}$ Carta de Santiago Avendaño a Botana, 5 de agosto de 1869, en Sarramone (1993, p. 187). 
abundante presencia aborigen y de un proceso de apropiación particular más tardío que el de Azul, que como vimos, había comenzado ya en las primeras décadas del siglo (LANTERI, 2008b, 2009-11). Finalmente, fueron registradas 8.000 has vendidas en Azul en 1880 y 2.715 y 1.773 en Tapalqué en 1879 y 1880, respectivamente, según la ley de ventas de tierras públicas de 1878 (VALENCIA, 2009, p. 129), una de las últimas normativas antes de la campaña militar del gral. Roca.

\section{El Caso de Villa Fidelidad}

En la descripción de este panorama, la experiencia seguida por el grupo del cacique pampa Maycá contrasta en varios aspectos con las trayectorias de otros grupos de "indios amigos" del oeste y sur bonaerense, adquiriendo rasgos particulares: Maycá recibió tierras en 1856, el mismo año de la realización del tratado de paz con Juan Catriel y varios años antes a las concesiones realizadas a las tribus del oeste bonaerense. Pero, a diferencia del reconocimiento de su asentamiento en las tierras del arroyo de Nievas logrado por Catriel y en contraste con las concesiones realizadas por el congreso provincial en años posteriores a otras tribus amigas, el acuerdo con Maycá significó la entrega de cien solares en propiedad individual a las distintas familias de su grupo que integraron una población denominada con el significativo nombre de "Villa Fidelidad".27

El caso de Maycá parece constituir una excepción, también, ya que la entrega de tierras fue realizada en terrenos adyacentes al pueblo de Azul y, por lo tanto, clasificables como zona urbana. ¿Cómo y por qué fue posible que un grupo indígena accediera a tierras bajo propiedad individual en una fecha tan temprana como 1856, cuando las siguientes experiencias de otorgamientos a comunidades indígenas muestran que la subdivisión de las mismas se consideraba un aspecto conflictivo y hasta impracticable?

A modo de hipótesis, pensamos que esta particular experiencia -que representa la primera entrega de tierras en propiedad a indígenas de la provincia de Buenos Aires- está sumamente vinculada a la posición que mantuvo el grupo de Maycá en los turbulentos años '50. La consulta de las listas de revista de los distintos cuerpos del ejército bonaerense para el año 1855 refleja que, en diferentes puntos de la frontera, el servicio miliciano de los "indios amigos" se mantuvo como acostumbraba suceder en tiempos rosistas (RATTO, 2010). Pero, a diferencia de dicho período, en el sector sur es donde menos participación indígena se registra, figurando solamente en la región de

27 El acta de fundación está fechada el 18 de octubre de 1856 (HUX, 1993, p. 130). Más detalles en De Jong, te al. (2009). 
Azul - Tapalqué, la división comandada por el cacique Maycá. La disminución de las milicias nativas no sorprende ya que, como se ha dicho, los grupos que respondían a Catriel y a Cachul se sublevaron luego del intento de traslado del cantón de Tapalqué y pasaron a formar parte de la Confederación de Calfucurá.

Se podría alegar que, si la entrega de tierras constituyó un premio por el servicio miliciano, todos los grupos indígenas que revistaron en el ejército en dicha coyuntura deberían haberlas recibido. Sin embargo, creemos que, precisamente, el hecho de tratarse del único grupo que mantuvo su adhesión al gobierno bonaerense cuando el resto de los habitantes nativos de la región pasó al enfrentamiento es un indicador sumamente significativo para sostener la hipótesis. A su vez, la misma forma de nominar el espacio otorgado apoya, en parte, dicha interpretación (RATTO, 2010).

Otro elemento sumamente novedoso en esta experiencia es que la tierra entregada a Maycá fue adquirida por el comandante Escalada a la Municipalidad de Azul. Hasta el momento no hemos encontrado registros contables del Estado de Buenos Aires que demuestren que el gasto de la compra fue cargado al presupuesto estatal. ¿Significa esto que los mismos vecinos cedieron el terreno a modo gratuito? El contexto de fuerte inseguridad que se había vivido pudo haber incidido en la disposición de los pobladores criollos locales a ofrecer acuerdos a aquellos caciques que garantizaran su protección ante los ataques indígenas.

Finalmente, queremos destacar un tercer elemento diferenciador en esta experiencia: la entrega de tierra adoptó la forma de suertes individuales para cada familia de la tribu. La modalidad empleada y aceptada por la agrupación de Maycá para la adjudicación de las tierras está haciendo referencia a procesos de mestizaje cultural y de incorporación de comunidades indígenas a las pautas organizativas estatales que, indudablemente, se venían operando al menos desde el funcionamiento del "negocio pacífico de indios" en la etapa rosista (QUIJADA, 2002; RATTO, 2003a).

\section{Conclusiones}

Las políticas estatales hacia la población indígena y no indígena a lo largo del siglo XIX en la zona de estudio fueron diferentes. Podría plantearse, en términos generales, que mientras las medidas tomadas con respecto a los pobladores "blancos" tendieron a asegurar el acceso de pequeños y medianos productores -en claro contraste con el resto de la campaña, donde predominó la gran propiedad- asegurando la ocupación y puesta en producción de las tierras al sur del Salado, las medidas tomadas en relación con la población indígena se realizaron con aquellos grupos que ingresaron 
como "indios amigos" al marco de la política del "negocio pacífico", y en función de asegurar la expansión territorial y protección de los primeros.

De esta forma, el fomento de la pequeña-mediana propiedad sobre la grande en la región de Azul y Tapalqué y el establecimiento in situ de las tolderías catrieleras durante el gobierno de Rosas continuó en gran medida hasta fines del siglo, con las particularidades propias de cada coyuntura. En el decenio de 1850 implicó el comienzo del acceso a la propiedad legal de las suertes y el reestablecimiento del "negocio pać́fico" por parte del Estado de Buenos Aires, en un contexto en el cual la territorialidad indígena y las cesiones de tierras en propiedad - por lo menos en el plano formal- a los grupos de "indios amigos" jugaron un papel central en los nuevos acuerdos interétnicos.

Con posterioridad a la caída del gobierno de Rosas y en el marco de la recomposición de los términos básicos del "negocio pacífico de indios" por parte del Estado nacional, volvieron a desplegarse medidas que favorecieron el asentamiento de grupos indígenas amigos en la frontera. Pero esta etapa tuvo características novedosas, en tanto en algunas jurisdicciones fronterizas se avanzó en medidas legislativas de concesión efectiva de tierras a algunos caciques y sus tribus.

La distribución de terrenos fue sin embargo marcadamente diferente según la zona de la provincia. Mientras que en el centro-oeste bonaerense y Bahía Blanca se entregaron títulos formales, no sucedió lo mismo en el área de estudio, ya que el reconocimiento de las veinte leguas cuadradas de tierra a las tribus catrieleras que había sido oficializado mediante el tratado de 1856 fue dejado sin efecto en 1875, como parte de otro tratado de paz que condicionaba a los grupos catrieleros a trasladarse a territorios en la nueva línea de fronteras (SARRAMONE, 1993, p. 179-183; LEVAGGI, 2000, p. 294-309; detalles en LANTERI; PEDROTTA, 2009).

Al respecto, es posible que cada jurisdicción fronteriza representara un contexto diferente, tanto en lo que concierne a la cantidad de población indígena en las fronteras y sus vínculos potenciales con los sectores indígenas de "tierra adentro" como en las prácticas locales y márgenes de poder de los funcionarios militares de frontera. Ambos aspectos revistieron en la zona de Azul, durante este período, aristas bastante complejas. La instalación de nuevos "indios amigos" provenientes de Salinas Grandes en las jurisdicciones de Azul y Bahía Blanca, donde se realizaba a su vez el abastecimiento de raciones de Calfucurá, había contribuido a generar una trama fluida y potencial de alianzas políticas, que sin embargo se contradecía con el rol formal de aliados políticos de los "indios amigos" que el orden estatal intentaba favorecer. Los "indios amigos" del Azul se encontraban así en un lugar ambiguo y fluctuante como 
eslabones de tramas de alianzas indígenas y de la administración estatal en las fronteras, en un marco en el que ambos sectores mantenían, aunque bajo la forma del "negocio pacífico", relaciones de fuerza y oposición.

A ello se agrega la relevancia numérica de la población indígena de Azul y Tapalqué en comparación con otros núcleos de la antigua línea de fronteras, reflejada en una también mayor cantidad de tierras ocupadas, rasgos que incidieron probablemente en las diferentes orientaciones de la legislación estatal sobre la tenencia indígena en el período analizado. Si bien en relación con los asentamientos de "indios amigos" del centro-oeste la política estatal tendió a favorecer el reconocimiento y la concesión de tierras a los caciques y sus tribus - aunque bajo la cláusula de futuras subdivisiones e imposibilidad de vender las tierras por un cierto lapso de tiempo- esta respuesta no se produjo ante los pedidos de concesión de los caciques tapalqueneros.

El próximo fin de las fronteras, la consecuente pérdida de funcionalidad política de los "indios amigos" en el panorama de expansión del dominio estatal y la articulación al mercado mundial sobre la región pampeana seguramente contribuyen a explicar la ausencia de medidas de concesión de tierras durante la década de 1870. En tal sentido, la redefinición de las políticas estatales hacia una solución ofensiva y militar del avance fronterizo, cada vez más clara desde el fin de la Guerra del Paraguay y la pronta extensión del ferrocarril y otros medios de comunicación -con las consecuentes ventajas económicas que este transporte daba a la producción para el mercado-, desalentaron otras medidas posibles tendientes a incorporar a los habitantes indígenas del sur bonaerense en términos de productores y propietarios individuales.

No obstante los resultados tangibles que el proceso de creación de la Argentina "moderna" tuvo para estos sectores, que quedaron mayormente relegados del Estado nacional, en este trabajo hemos querido presentar la complejidad y dinámica propias de cada coyuntura durante el continuum del siglo XIX, rescatando a los grupos indígenas y campesinos como hacedores efectivos de los procesos coetáneos, cuyos reclamos de bienes patrimoniales y derechos de propiedad territorial llegan hasta la actualidad y se encuentran a la luz de nuestro pasado-presente nacional. 


\section{Referencia}

ARCHIVO del General Mitre. Buenos Aires: Biblioteca de la Nación, 1912.

ARENA, J osé; CORTÉS, J ulio; VALVERDE, Alberto. Ensayo histórico del partido de Olavarría. Olavarría: Municipalidad de Olavarría, 1967.

BANZATO, Guillermo; LANTERI, Sol. Forjando la frontera: políticas públicas y estrategias privadas en el Río de la Plata, 1780-1860. Historia Agraria: revista de agricultura e historia rural, Murcia, n. 43, p. 435-458, 2007.

BARRAL, María Elena; FRADKIN, Raúl. Los pueblos y la construcción de las estructuras de poder institucional en la campaña bonaerense (1785-1836). In: FRADKIN, Raúl (Comp.). El poder y la vara: estudios sobre la justicia y la construcción del Estado en el Buenos Aires rural. Buenos Aires: Prometeo, 2007.

BARROS, Álvaro. Fronteras y territorios federales de las pampas del sur. Buenos Aires: Solar, 1975.

BARSKY, Osvaldo; DJ ENDEREDJ IAN, J ulio. Historia del capitalismo agrario pampeano: la expansión ganadera hasta. Buenos Aires: Siglo Veintiuno, 2003. t. 1.

BELLONI, Carolina. La política indígena del estado de Buenos Aires en la frontera sur: Azul y Tapalqué entre 1852 y 1862. 2010. Tesis (Doctorado) - Facultad de Filosofía y Letras, Universidad de Buenos Aires, Buenos Aires.

CANSANELLO, Carlos. De súbditos a ciudadanos: ensayo sobre las libertades en los orígenes republicanos. Buenos Aires, 1810-1852. Buenos Aires: Imago Mundi, 2003.

CAPDEVILA, Ramón. Tapalqué en la historia. Tapalqué, 1963.

COPELLO, Santiago. Gestiones del arzobispo Aneiros a favor de los indios hasta la Conquista del Desierto. Buenos Aires: Difusión, 1994.

DEJ ONG, Ingrid. Acuerdos y desacuerdos: política estatal e indígena en la frontera bonaerense (1856-1866). In: Mandrini, R.; A. Escobar Ohmstedey S. Ortelli (Ed.). Sociedades en Movimiento: los pueblos indígenas de América Latina en el siglo XIX. Tandil: Universidad Nacional del Centro de la Provincia de Buenos Aires, 2007. p. 47-62.

. Funcionarios de dos mundos en un espacio liminal: los `indios amigos' en la frontera de Buenos Aires (1856-1866). Cultura-Hombre-Sociedad (CUHSO), Temuco, $n$. 15, p. 75-95, 2008.

DE J ONG, Ingrid; LANTERI, Sol; PEDROTTA, Victoria; RATTO, Silvia. Políticas oficiales y territorialidad indígena en la frontera sur bonaerense durante el siglo XIX: el caso de Villa Fidelidad (1856-2009). In: J ORNADAS DE ESTUDIOS INDÍGENASY COLONIALES. 2009, J ujuy. Anales... J ujuy: CEIC, 2009.

DE J ONG, Ingrid; RATTO, Silvia. Redes políticas en el área Arauco-pampeana: la confederación indígena de Calfucurá (1830-1879). Intersecciones en Antropología, Olavaria, n. 9, p. 241-260, 2008. 
DURÁN, J uan Guillermo. En los toldos de Catriel y Railef: la obra misionera del Padre J orge María Salvaire en Azul y Bragado, 1874-1876. Buenos Aires: Facultad de Teología, 2002.

FERRER, Eduardo; PEDROTTA, Victoria. Los corrales de piedra: comercio y asentamientos aborígenes en las sierras de Tandil, Azul y Olavarría. Tandil: Crecer, 2006.

FISCHMAN, Gustavo; HERNANDEZ, Isabel. La ley y la tierra: historia de un despojo en la tribu mapuche de Los Toldos. Buenos Aires: UBA-Centro Editor de América Latina, 1990.

HALPERIN DONGHI, Tulio. La expansión ganadera en la campaña de Buenos Aires (1810-1852). Desarrollo Económico, Buenos Aires, n. 3, p. 57-110, 1963.

. Una nación para el desierto argentino. Buenos Aires: Prometeo, 2005.

HUX, Meinrado P. Caciques puelches pampas y serranos. Buenos Aires: Marymar, 1993.

INFESTA, María Elena. La pampa criolla: usufructo y apropiación privada de tierras públicas en Buenos Aires, 1820-1850. La Plata: Archivo Histórico de la Provincia de Buenos Aires, 2003.

. Propiedad rural en la frontera: Azul, 1839. In: BARBA, Enrique. In Memoriam: estudios de historia. Buenos Aires: Banco Municipal de La Plata, 1994. p. 269-286.

LANTERI, Sol. ¿Una frontera bárbara y sin instituciones? elecciones y clientelismo en la formación del estado provincial durante el gobierno de Rosas. Prehistoria, Rosario, año 12 , n. 12, p. 15-40, 2008 a.

. Estado, tierra y poblamiento en la campaña sur de Buenos Aires durante la época de Rosas: la frontera del arroyo Azul. Anuario de Estudios Americanos, Sevilla, n. 62 , v. 2, p. 251-283, 2005.

Estado, tierra y sociedad rural en la conformación del orden fronterizo: Azul y Tapalqué, 1852-1857. In: CONICET. Proyecto de Investigación de Beca Interna Postdoctoral, 2009-2011. 2011.

. Pobladores y donatarios en una zona de la frontera sur durante el rosismo: el arroyo Azul durantela primera mitad del siglo XIX. Quinto Sol: Revista de Historia Regional, Santa Rosa, n. 6, p. 11-42, 2002.

. Un vecindario federal: la construcción del orden rosista en la frontera sur de Buenos Aires (Azul y Tapalqué). Tesis (Doctoral) - Instituto de Estudios Histórico Sociales, Universidad Nacional del Centro de la Provincia de Buenos Aires, Tandil, $2008 \mathrm{~b}$.

Un vecindario federal: políticas oficiales y "servicios a la patria" en la frontera sur bonaerense durante el gobierno de Rosas. Secuencia: Revista de Historia y Ciencias Sociales. México, n. 81, 2011. 
Una verdadera "isla en el nuevo sur": las donaciones condicionadas en el arroyo Azul durante el rosismo. Mundo Agrario: Revista de estudios rurales, La Plata, v. 7, n. 14, 2007. Disponible en: <http: www.mundoagrario.unlp.edu.ar>. Acceso en: 2011.

LANTERI, Sol; PEDROTTA, Victoria. Mojones de piedra y sangre en la pampa bonaerense: estado, sociedad y territorio en la frontera sur durante la segunda mitad del siglo XIX. Estudios Trasandinos, v. 15, n. 1, p. 101-129, 2009.

LANTERI, Sol; SANTILLI, Daniel. Consagrando a los ciudadanos: procesos electorales comparados en la campaña de Buenos Aires durante la primera mitad del siglo XIX. Revista de Indias, Madrid, v. 70, n. 249, p. 551-582, 2010.

LEVAGGI, Abelardo. Paz en la frontera: historia delas relaciones diplomáticas con las comunidades indígenas en la Argentina (siglos XVI-XIX). Buenos Aires: Universidad del Museo Social Argentino, 2000.

PEDROTTA, Victoria. Las sociedades indígenas del centro de la provincia de Buenos Aires entre los siglos XVI y XIX. 2005. Tesis (Doctoral) - Facultad de Ciencias Naturales y Museo, Universidad Nacional de La Plata, La Plata.

QUIJ ADA, Mónica. Repensando la frontera sur argentina: concepto, contenido, continuidades y discontinuidades de una realidad espacial y étnica (siglos XVIII-XIX). Revista de Indias, Madrid, v. 62, n. 224, p. 103-142, 2002.

RATTO, Silvia. Conflictos y armonías en la frontera bonaerense (1832-1840). Entrepasados: Revista de Historia, Buenos Aires, n. 11, p. 21-34, 1996.

. El negocio pacífico de los indios: la frontera bonaerense durante el gobierno de J uan Manuel de Rosas (1829-1852). Siglo XIX, México, n. 15, p. 25-47, 1994a.

. Indios amigos e indios aliados: orígenes del negocio pacífico en la provincia de Buenos Aires (1829-1832). Buenos Aires: FFyL- UBA, 1994b. Cuadernos del Instituto Ravignani, v. 5.

La defensa de la frontera de Buenos Aires durante la década de 1850: una aproximación a través del análisis de las listas de revista. 2010. Mimeo.

. La frontera bonaerense (1810-1828): espacio de conflicto, negociación y convivencia. La Plata: Archivo Histórico de la Provincia de Buenos Aires, 2003a.

. Soldados, milicianos e indios de "lanza y bola": la defensa de la frontera bonaerense a mediados de la década de 1830. Anuario IEHS, Tandil, n. 18, p. 123-152, 2003b.

SAENZ QUESADA, María. La república dividida, 1852-1855. Buenos Aires: La Bastilla, 1979.

SARRAMONE, Alberto. Catriel y los indios pampas de Buenos Aires. Azul: Biblos, 1993.

SCOBIE, J ames. La lucha por la consolidación de la nacionalidad argentina, 18521862. Buenos Aires: Solar, 1964. 
VALENCIA, Marta. La última frontera de la provincia de Buenos Aires antes de la campaña de Roca. In: BLANCO, Graciela; BANZATO, Guillermo. La cuestión de la tierra pública en Argentina: 90 años de la obra de Miguel Ángel Cárcano. Rosario: Prohistoria, 2009. p. 111-132.

. Tierras públicas, tierras privadas: Buenos Aires, 1852-1876. La Plata: Universidad Nacional de La Plata, 2005.

ZEBERIO, Blanca. Un mundo rural en cambio. In: GOLDMAN, Noemí; BONAUDO, Marta. Nueva historia Argentina: liberalismo, estado y orden burgués (1852-1880). Buenos Aires: Sudamericana, pp. 293-362, 1999.

\section{La zona de estudio y el avance de la frontera en el siglo XIX}

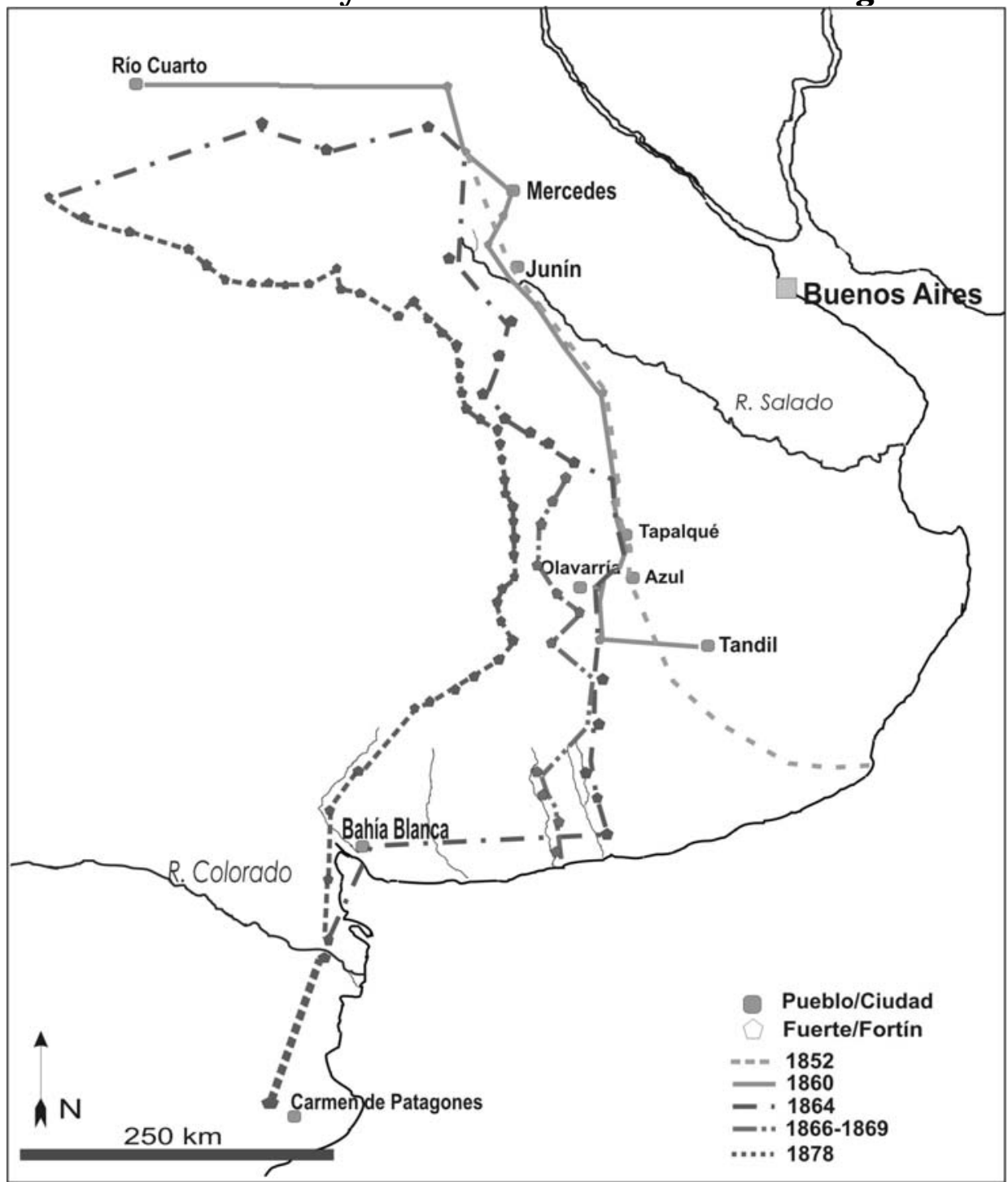

Colaboración recibida en 12/ 08/2011 y aprobado en 18/09/2011. 